\title{
Visualising space and time in crime patterns: A comparison of methods
}

\author{
Chris Brunsdon ${ }^{\mathrm{a}, *}$, Jonathan Corcoran ${ }^{\mathrm{b}}$, Gary Higgs ${ }^{\mathrm{b}}$ \\ a Department of Geography, Bennett building, University of Leicester, University Road, Leicester LE1 7RH, UK \\ ${ }^{\mathrm{b}}$ GIS Research Centre, School of Computing, University of Glamorgan, Pontypridd, Mid Glamorgan, \\ CF37 1DL, UK
}

Received 30 April 2004; received in revised form 4 July 2005; accepted 4 July 2005

\begin{abstract}
Previous research exploring space-time patterns has focused on the relative merits and drawbacks of the effectiveness of static maps vis-à-vis interactive dynamic visualisation techniques. In particular, they have tended to concentrate on the role of animation in interpretation of patterns and the understanding of underlying factors influencing such patterns. The aim of this paper is to broaden this debate out to consider the effectiveness of a wider range of visualisation techniques in permitting an understanding of spatio-temporal trends. The merits of three visualisation techniques, (map animation, the comap and the isosurface) are evaluated on their ability to assist in the exploration of space-time patterns of crime disturbance data. We conclude that each technique has some merit for crime analysts charged with studying such trends but that further research is needed to apply the techniques to other sources of crime data (and to other sectors such as health) to permit a comprehensive evaluation of their respective strengths and limitations as exploratory visualisation tools. (c) 2006 Published by Elsevier Ltd.
\end{abstract}

Keywords: Geo-visualisation; Spatio-temporal visualisation; Crime mapping; Comaps; Isosurfaces; Animation

\footnotetext{
${ }^{*}$ Corresponding author.

E-mail address: cb179@le.ac.uk (C. Brunsdon).
}

0198-9715/\$ - see front matter (C) 2006 Published by Elsevier Ltd doi:10.1016/j.compenvurbsys.2005.07.009 


\section{Introduction}

Knowing something about how patterns of crime are distributed across space provides us with knowledge that can be used to inform the allocation of police resources, to identify "hot-spots" and to analyse the effectiveness of crime prevention programmes such as Neighbourhood Watch schemes and CCTV installations. There have been a number of books concerned with applying GIS-based spatial data analysis tools to crime data (see for example Goldsmith, McGuire, Mollenkopf, \& Ross, 2000; Hirschfield \& Bowers, 2001; Leipnik \& Albert, 2003; Weisburd \& McEwen, 1998; for overviews of the current state of play in crime mapping and for detailed case studies). There are now national (and international) crime mapping conferences given over to demonstrating the capabilities of analytical tools in a host of application areas. In addition commercial software tools, either as stand-alone packages (e.g. CrimeStat - Levine (1999)) or as part of a extensions to standard GIS packages (e.g. the CRIMEVIEW extension to ArcView), are available with which to analyse spatially disaggregate crime data. In addition to analysing spatial patterns, it is also important have an appreciation of how the distribution of crime locations change over time and a number of studies (reviewed in this paper) have developed tools which incorporate a temporal dimension to the analysis of crime patterns. There have been a number of studies that have examined the use of dynamic visualisation in spatio-temporal mapping (e.g. Andrienko, Andrienko, \& Gatalsky, 2003; Dykes, 1996; Koussoulakou \& Kraak, 1992; Shepherd, 1995). This paper adds to this body of literature by applying for the first time (to our knowledge) new visualisation techniques to a database detailing police call-outs to disturbances for an urban centre that, we argue, reveals new insights into the patterns of disturbances in space and time.

The rest of the paper is structured as follows. In Section 2 we briefly review previous research that has examined the potential of visualisation techniques as part of an exploratory data analysis approach. We draw on this literature to highlight gaps in our knowledge in this field and to demonstrate the need for research that compares the effectiveness of a range of interactive and dynamic visualisation tools. One area where such techniques have real potential is that of crime mapping and in Section 3 we review, previous research in this area concerned specifically with the use of a range of visualisation tools. In the fourth part of the paper, we describe the data sets used in our study area before demonstrating the use of three visualisation techniques applied to this point level data set in order to study spatial and temporal variations in the incidence of such data. In the final section of the paper we summarise the advantages (and current limitations) of these techniques in providing insights into patterns of point level data before highlighting a number of avenues for further investigation following on from this research.

\section{Geo-visualisation and new techniques}

Geographic visualisation is an area that has been the focus of much research, (for a review see for example, MacEachren \& Kraak, 2001). MacEachren (1994) drew attention to a theoretical framework that included the need to consider how such representations are used, the objectives of the visualisation and the degree of interactivity. There has been a significant amount of research that has investigated the appropriateness of, for example, 2D static maps and 3D interactive maps (Slocum et al., 2001). These can include animated and interactive maps and provide useful tools in a variety of exploratory tasks (Andrienko 
\& Andrienko, 1999; MacDougall, 1992). Indeed many of the visualisation techniques developed to discern trends in spatial data derived from some of the earlier work concerned with linking GIS with exploratory techniques (e.g. Dykes, 1997a; Haining, Wise, \& Ma, 1996; Haslett, Wills, \& Unwin, 1990). Andrienko et al. (2003) draw attention to two major factors that could potentially influence the nature of the visualisation technique used; namely the types of spatio-temporal data being analysed and the exploratory tasks they are used to support. Fairbairn, Andrienko, Andrienko, Buziek, and Dykes (2001) suggest that important research challenges need to be addressed in relation to five aspects of representation, namely: the nature of geospatial data, the need to formalise a theory of the form of representation, to consider the purpose of the representation, to understand the needs of the user and familiarisation with the tools and technology involved in different visualisation methods. However, more research is needed on the applicability of certain techniques in relation to the applications in hand. In particular such methods vary according to levels of user interactivity permitted that, in turn, controls user input and behaviour.

Slocum et al. (2001) draw attention to the advantages of dynamic visualisation in exploring temporal changes in spatial data through user interaction and manipulation of mapped displays but also highlight the fact that more research needs to be conducted on the effectiveness of such tools. Drawing on six principal research themes, including that of dynamic representations, their study highlighted the importance of cognitive and usability issues and suggests the need for new cognitive theory in relation to interactive and immersive geo-visualisation. Several studies, reviewed by Slocum and colleagues, have drawn attention to the limitations of animation in permitting users a comprehensive understanding of the phenomenon of interest (e.g. Morrison, Tversky, \& Betrancourt, 2000). Other studies have suggested that the use of animation in some application areas with expert audiences can provide insight into spatio-temporal patterns that were established from the use of alternative techniques (e.g. MacEachren, Boscoe, Haug, \& Pickle, 1998). However, few studies have compared the effectiveness of different techniques for visualising changes that use the same source of temporally changing geo-coded data. Important research questions need to be addressed in such research. For example:

- Do the interpretations of spatial-temporal trends vary according to the types of visualisation techniques employed?

- Is there one techniques that can be favoured over another, or is a combination of such techniques the preferred option in order to enhance understanding of underlying spatial patterns?

- Will the nature of the techniques applied vary according to the type of data available?

- Will the effectiveness of these techniques very with user experience?

One of the cross-cutting research challenges highlighted by MacEachren and Kraak (2001, p. 9) concerns the need "to develop extensible methods and tools that enable understanding of, and insight to be derived from, the increasingly large and complex geospatial data sets available". This echoes Dykes (1997a, p. 346) call for the need for more "experimentation with cartographic representation" in order to examine the "potential for using multiple cartographic representations of data sets" to enable data sets to be explored from different perspectives. In this paper we are primarily concerned with exploring the use of a broader set of tools that can be used to visualise dynamically changing features or incidents; using the example of geo-coded crime data. Whilst there has been some research 
on the effectiveness of dynamic (and in particular animated) maps vis-à-vis static maps (see for example, Slocum \& Egbert, 1993), the principal aim in this paper is to draw attention to the advantages (and limitations) of a range of new visualisation tools applied to the same data set in terms of interpretation of trends.

\section{Previous studies in crime mapping}

Mapping crime to elicit information concerning its spatial distribution has a long history. Some of the earliest uses of crime mapping can be traced back as far as the 19th century in France (Guerry, 1833; Quètelet, 1842), where maps were utilised to visualise and analyse crime information. The advent of computing and growth of GIS technologies has undoubtedly fuelled the development of a range of crime mapping systems. Such systems have now become more commonplace in operational policing environments where they are employed for a variety of real-time (resource allocation) and non-real time analytical procedures that help inform policing strategy. The rapid growth in the uptake of computerised mapping technologies by police forces has been noted in surveys in both the US (Mamalian \& LaVigne, 1999) and in the UK (Corcoran \& Ware, 2002), the trend is set to continue.

The prevalence of crime mapping among both practitioners and researchers has been recognised with the establishment of the US based MAPS (Mapping and Analysis for Public Safety) research centre in 1997 (http://www.ojp.usdoj.gov/nij/maps/), and the UK Jill Dando Institute of Crime Science in 2000 (http://www.jdi.ucl.ac.uk/). These centres are additionally host to two independent crime mapping conferences that run annually. A quarterly newsletter entitled Crime Mapping News (Police Foundation, 2005) publishes a range of articles pertaining to the operational application of crime mapping, software, up-coming conferences and training programs. In addition a crime mapping listserv (supported by the MAPS program) has been established to encourage the discussion of issues (largely technical and methodological), related to crime data and its analysis plus the announcement of forthcoming training and conferences. The ability to pinpoint and visualise the locations of criminal acts permits a range of geographical techniques to be applied, including point, aggregate and surface visualisations. Table 1 presents a summary of visualisation techniques that have been applied in crime mapping studies.

Each type of visualisation has the potential to inform the user of spatial distributions from which issues such as vulnerability can be identified. However, what is more difficult is to depict are changes in the vulnerability of these identified areas over time. This paper presents three different types of visualisation (map animation, the comap and the isosurface) each of which is capable of representing space-time patterns. Following a case study the merits of each approach are then presented.

\section{Methodology}

Three visualisation techniques were applied to data detailing police call-outs to disturbances for an urban centre and its surrounding region covering the period 1999-2001. The study region is approximately 10 miles from east to west. Each disturbance that is reported to the police is logged in this incident data set that contains a date, time and its location ( $x$, $y$ coordinate). Although there are various weaknesses associated with this source of data that include both under and over-reporting (for a fuller discussion see for example, 
Table 1

Visualisation techniques applied in crime mapping studies

\begin{tabular}{|c|c|c|c|c|c|}
\hline Author & Geographical area & $\begin{array}{l}\text { Visualisation } \\
\text { technique }\end{array}$ & Aim of study & Results \& conclusions & $\begin{array}{l}\text { Limitations/drawbacks of } \\
\text { technique }\end{array}$ \\
\hline $\begin{array}{l}\text { McEwen and } \\
\text { Taxman } \\
(1995)\end{array}$ & $\begin{array}{l}\text { Multiple localities } \\
\text { used }\end{array}$ & Point mapping & $\begin{array}{l}\text { Demonstrate the three general } \\
\text { mapping techniques } \\
\text { (descriptive, analytical and } \\
\text { interactive) }\end{array}$ & $\begin{array}{l}\text { Point mapping was used to } \\
\text { demonstrate the utility of } \\
\text { descriptive mapping for } \\
\text { identifying localities of crimes } \\
\text { and arrests }\end{array}$ & $\begin{array}{l}\text { When the concentration } \\
\text { crime is both high and th } \\
\text { same location is subject t } \\
\text { multiple incidences, using } \\
\text { point visualisation can gi } \\
\text { unrepresentative view of } \\
\text { data (multiple incidence } \\
\text { localities appearing as a s } \\
\text { point) }\end{array}$ \\
\hline $\begin{array}{l}\text { Thomas et al. } \\
\text { (1996) }\end{array}$ & $\begin{array}{l}\text { Cardiff city-centre, } \\
\text { Wales }\end{array}$ & $\begin{array}{l}\text { Variable symbol } \\
\text { mapping }\end{array}$ & $\begin{array}{l}\text { Investigate space-time patterns } \\
\text { of shoplifting. Variable symbol } \\
\text { mapping was used to visualise } \\
\text { locations of shoplifting } \\
\text { incidents }\end{array}$ & $\begin{array}{l}\text { The spatial analysis confirmed } \\
\text { various aspects of shoplifting, } \\
\text { noting marked concentrations } \\
\text { in particular areas that could } \\
\text { be attributed to opportunities }\end{array}$ & $\begin{array}{l}\text { Although this technique } \\
\text { alleviate some of the } \\
\text { drawbacks associated wit } \\
\text { point mapping (noted ab } \\
\text { the use of variable symbo } \\
\text { create problems of overla } \\
\text { symbols particularly whe } \\
\text { concentration of crime is } \\
\text { - occluding the true } \\
\text { distribution in addition t } \\
\text { other underlying map lay }\end{array}$ \\
\hline $\begin{array}{l}\text { Brimicombe } \\
\text { et al. (2001) }\end{array}$ & $\begin{array}{l}\text { Newham (London } \\
\text { Borough) }\end{array}$ & $\begin{array}{l}\text { Choropleth } \\
\text { mapping }\end{array}$ & $\begin{array}{l}\text { Assess geographical patterns of } \\
\text { racially motivated crimes and } \\
\text { harassment using wards as the } \\
\text { spatial unit }\end{array}$ & $\begin{array}{l}\text { The spatial analysis } \\
\text { demonstrated the utility of this } \\
\text { technique to explore and } \\
\text { visualise the data and to } \\
\text { highlight aspects that warrant } \\
\text { further investigation }\end{array}$ & $\begin{array}{l}\text { Imposing administrative } \\
\text { boundaries can produce } \\
\text { misleading results, for ex } \\
\text { where locations of high } \\
\text { incidence are trans-bounc } \\
\text { the resulting intensity (wl } \\
\text { represented using a boun } \\
\text { network) will be diluted }\end{array}$ \\
\hline
\end{tabular}



McLafferty et al. None used
$(2000)$

Openshaw and

Tyneside,

Dorling

Newcastle, UK

(1992)

Langworthy and Jefferis (2000)

The Bronx, New York, US

\section{Bowers and Johnson} (2003)

Liverpool and
Lancashire
(Northwest
England)
England)

\section{Pellenbarg and} Van Steen (2000)
Kernel density estimation

Present the application, advantages and challenges of using kernel density estimation for analysing crime data

Map animation

The use of kernel density estimation offers an efficient technique by which large volumes of crime data can be analysed for the detection of hotspots

Assess map animation as a tool to explore space-time data using crime, cancer and leukaemia data

Standard deviation ellipses

Using standard deviation ellipses, the effect of schooling hours on the spatial arrangement of burglaries was assessed. This was achieved by comparing the mean centres, diffusion of distributions, shape of the distribution and analysing the clusters for each standard deviation ellipse

Measure geographical displacement of crime
No great discovers of unknown patterns, however this could be improved by focusing of specific crimes at specific locations and times Results for each of the statistical descriptors (e.g. mean centre, diffusion of distribution, etc.) showed little support for schooling hours determining burglary patterns. However, it must be noted that the main purpose of this paper was to present the utility of this technique

Buffer zones (using both aggregate and disaggregate data) were successfully used as part of a methodology to assess whether or not crime had been displaced following a crime prevention exercise in a given area
The determination of an appropriate $h$ or smooth value

How this type of visualis is perceived and interpret comparison to more tradi representations (i.e. poin aggregate mapping)

The time required to crea animation from the raw Restriction due to the lac interactivity

Delineation of a hotspot using ellipses may be unrepresentative of the hotspot boundaries Can produce ambiguous results where the distribut multimodal

Determination of the size the buffer areas and their influence upon the analys 
Table 1 (continued)

\begin{tabular}{|c|c|c|c|c|c|}
\hline Author & $\begin{array}{l}\text { Geographical } \\
\text { area }\end{array}$ & $\begin{array}{l}\text { Visualisation } \\
\text { technique }\end{array}$ & Aim of study & Results \& conclusions & $\begin{array}{l}\text { Limitations/drawbacks } \\
\text { of technique }\end{array}$ \\
\hline $\begin{array}{l}\text { Venezia and } \\
\text { Kane (2002) }\end{array}$ & $\begin{array}{l}\text { Jacksonville, } \\
\text { Florida, US }\end{array}$ & $\begin{array}{l}\text { 3-Dimensional } \\
\text { mapping }\end{array}$ & $\begin{array}{l}\text { Present the potential utility of } \\
\text { a 3-Dimensional city-wide } \\
\text { model in a hostage situation }\end{array}$ & $\begin{array}{l}\text { Users are able to perform } \\
\text { geospatial queries to return } \\
\text { information concerning } \\
\text { building design (e.g. how many } \\
\text { floors and locations of exits), } \\
\text { and locate police officers and } \\
\text { emergency vehicles within the } \\
\text { visualisation }\end{array}$ & $\begin{array}{l}\text { Familiarity of users with } \\
\text { models } \\
\text { Costs of data collection, } \\
\text { storage and maintenance } \\
\text { addition to the costs of } t \\
\text { hardware required to sup } \\
\text { visualisation of the } 3 \mathrm{D} m\end{array}$ \\
\hline
\end{tabular}


Sherman, Gartin, \& Buerger, 1989) the analysis of incident data still provides a valuable indicator of police resource demand.

For each visualisation technique kernel density estimation (KDE) (Silverman, 1986) is used in order to create a 'risk surface' from the underlying police incident point data. The use of KDE is of particular utility with volume crimes (such as disturbances used here) where one location may be the locality for multiple incidents, thus representation in point format can occlude the true risk, whilst not being constrained to a boundary as with aggregate mapping.

\subsection{The map animation approach}

Applying cartographic animation to explore space-time problems has been established for over 30 years since the work of Tobler (1970) in his investigation of urban growth and that of Moellering (1976) who used animation to explore patterns of road traffic accidents. More recently, Curtis, Leitner, and Hanlon (2002) have used animation techniques as part of an overall exploratory data analysis tool used to examine spatio-temporal patterns in an infectious disease (racoon rabies) in West Virginia. Specifically, they used clustering techniques in order to identify local areas of interest prior to running animation software on individual disease cases. Results from the animation led the researchers to conclude that "visualising an infectious disease in this manner can provide greater insight into disease spread and control than can be achieved by modelling alone" (Curtis et al., 2002; p. 168).

The layer snapshot concept (Fig. 1) using a raster structure has been applied to modelling the temporal dynamics of many forms of spatial data such as crime (see for example, the UK's Crime Reduction toolkits - http://www.crimereduction.gov.uk) and weather (see for example, the UK's National Meteorological Office - http://www.metoffice.gov.uk). Each snapshot is a representation of a particular time period and state of particular

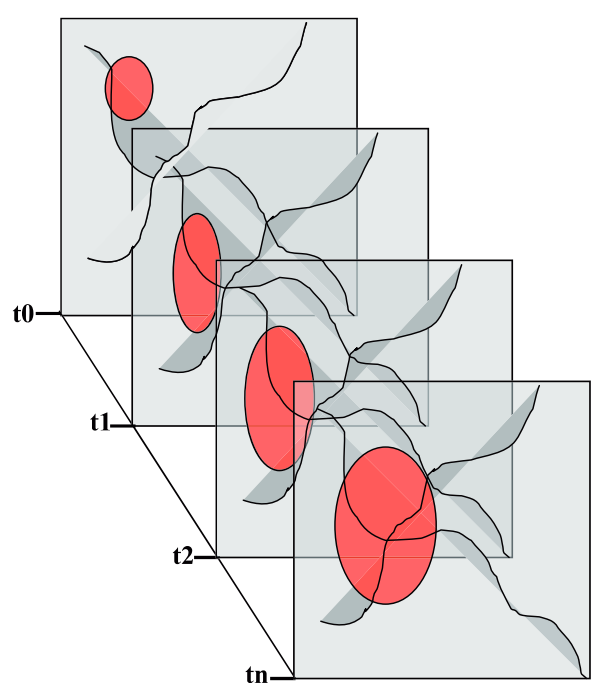

Fig. 1. The snapshot model. 
phenomena. The technique of animation takes this fundamental structure combining the various snapshots into a continuous sequence, that, when played, simulates the illusion of movement (Dorling, 1992).

Despite various criticisms of the snapshot model concerning data redundancy, (due to data replication) its use has proved a promising tool, allowing basic spatial analysis and facilitating fundamental questions to be addressed, such as:

- What is going on?

- Is there anything interesting?

- What is happening where and when?

- Are there any discernible patterns? (Openshaw, Waugh, \& Cross, 1994, p. 132).

The use of animation techniques for research and visual analysis may, however, be seen as having somewhat of a stigma attached to them as a result of their widespread use and associations with computer games and cartoon type products, in effect hiding their potential to address important research questions (Johnson, 1997). However, it has been shown in previous research that the use of animation has great potential to enhance the display of spatio-temporal information and to provide insights into patterns of a variety of spatial phenomena (see for example, Acevedo \& Masuoka, 1997; Batty, 1995; DiBiase, MacEachren, Krygier, \& Reeves, 1992; Dorling \& Openshaw, 1991; Gould, 1989; Openshaw, Charlton, Craft, \& Birch, 1988). Openshaw et al. (1994) used animation to explore police incident data for Tyne and Wear. Openshaw noted the ability to distinguish peaks in public disorder events, however observations at certain periods could not be readily explained, emphasising the role of an expert (i.e. a police officer) to provide further insight into the observed spatio-temporal patterning depicted by the animation. A second investigation employed animation to explore the relationship between crime and ambient temperature in which every crime was assigned a temperature value and mapping was generated for every $0.1 \mathrm{~K}$ between 3 and $25^{\circ} \mathrm{C}$. The results indicated a rise of public disorder events with increases in the ambient temperature. Thus, the use of animation in crime studies has great potential but remains relatively under utilised.

The animation software used here was developed in Visual Basic (Fig. 2) and implemented the raster snapshot model, incorporating a range of map and playback tools (discussed later) to facilitate user interactivity. The software was based on a stopwatch metaphor, combining the standard playback controls (i.e. play, stop, pause and frame rate), map controls (i.e. zoom and pan) however, additionally included a lap button (Fig. 3). As with a standard stopwatch the user can use the lap button to record a particular point in a sequence, here the animation lap button was used to record interesting subsets of the animated sequence. The user can manipulate what is contained within any subset using the map controls, selecting either the entire map or smaller subsets of the animation deemed interesting. Any number of these subsets can be taken, and viewed as a static image either in conjunction or in isolation with animated sequence. This was achieved by incorporating open source thumbnail viewing software (Gimenez, 2001).

One potential problem in the use of animation as an exploratory tool is the ability of the user to remember all pertinent aspects of the animated sequence. This is especially true for both longer and more complex animations where early frames may be overlooked as the user progresses towards the end of the sequence. The lap button was used here in an attempt to alleviate this situation. 


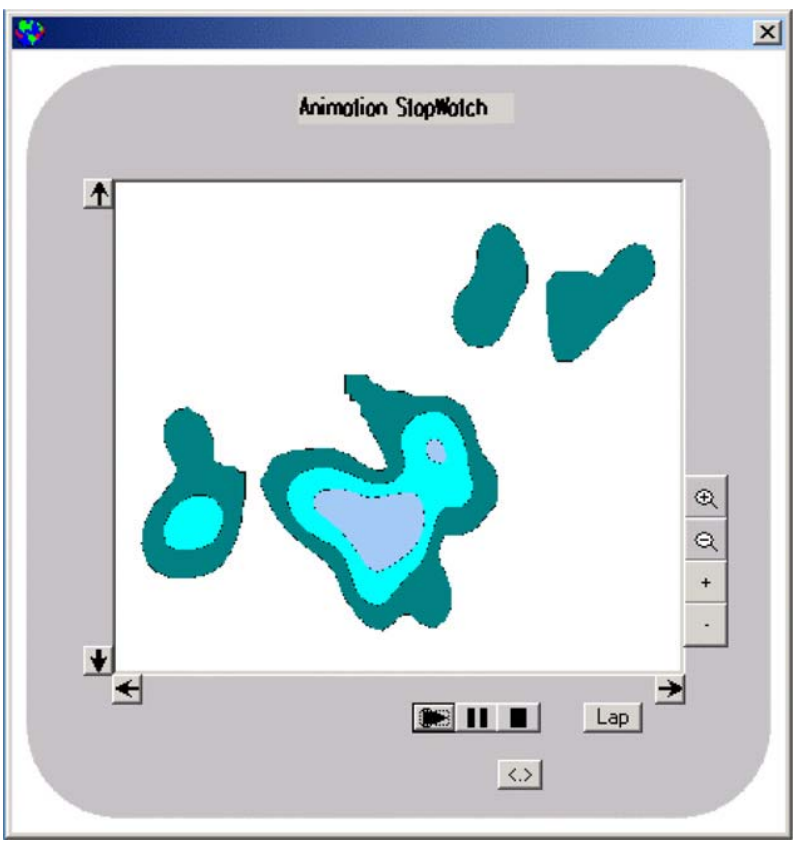

Fig. 2. The animation stopwatch.

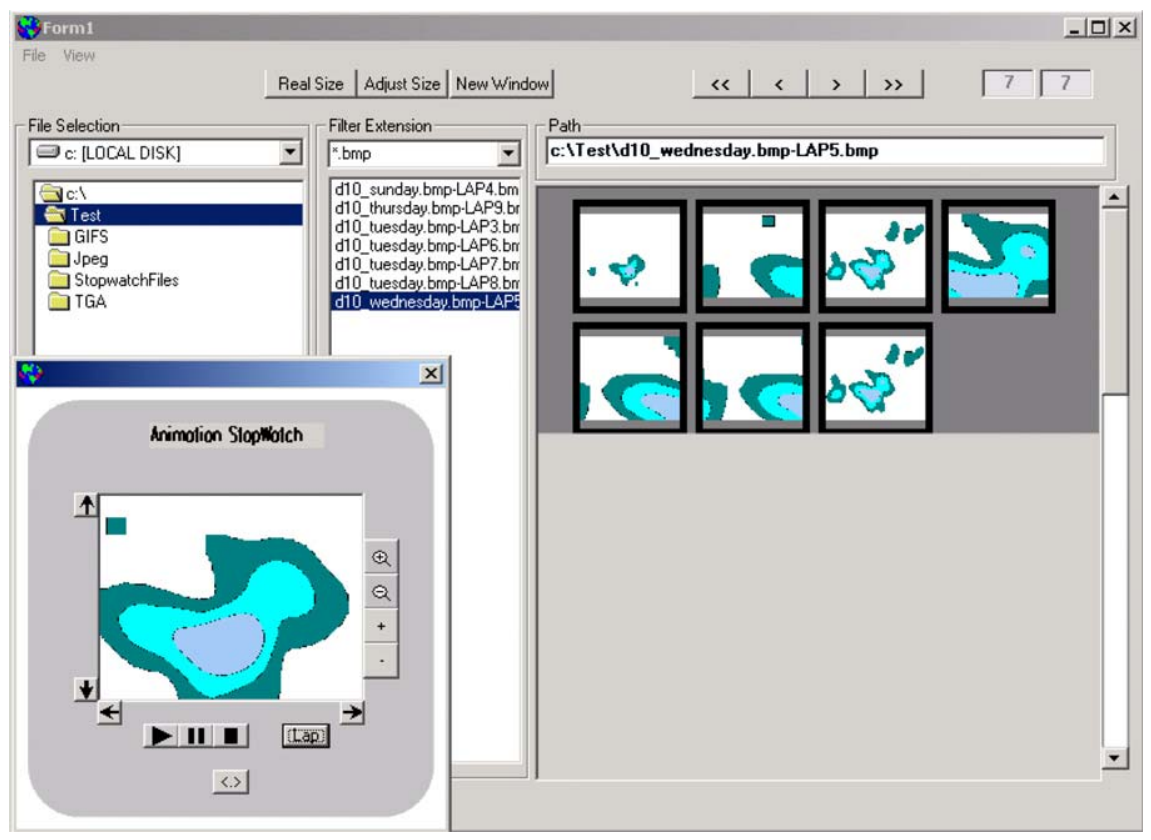

Fig. 3. The lap control 
In order to create and animate a crime sequence the temporal granularity was first decided (for example, day of week or hour of day), the data then subset into their appropriate time slices. The data pertaining to each time slice was then processed in ArcView using the Animal Movement extension (Hooge \& Eichenlaub, 2000) in order to produce a series of risk surfaces (one risk surface per time slice). A raster image of each risk surface is then generated. The animation software was then used to load and order the raster time slices to form an animated sequence that was viewed and explored using the various embedded playback and map tools described above.

Results from the animation permitted the identification of key epochs and localities that were subject to the majority of the incidents. The results demonstrated that the incidents tended to be concentrated within relatively small well-defined regions that both modify in area and distribution over time. This was most marked during the weekend days (i.e. Friday, Saturday and Sunday)

The interactive environment proved an advantage in hypothesis generation. The ability to alter the speed of the animation to focus on key epochs proved useful. For example, a spread of disorder was prominent between specific days and locations particularly notable at specific frame rates. This coupled with the ability pause and recommence and take lap snapshots of the animation facilitated the identification of this phenomenon.

The use of 'risk surfaces' in the animation provided an easily interoperable sequence from which such epoch to epoch changes were readily discernible. For example, the user was able to focus on a single probability area (e.g. the $50 \%$ probability area) and track its evolution throughout the animation sequence. Any major, satellite or transient areas (50\% probability areas) could easily be identified and associated with both a time and locale. Overlaying topographic layers, (e.g. boundary, building and roads) could then be used to facilitate a deeper understanding of any identified phenomena, and thus could be used to aid in the design of an appropriate policing response. However, it was recognised that the role of an expert (i.e. a police officer) could have provided still further explanation, echoing the findings of Openshaw et al. (1994).

\subsection{The comap approach}

The comap approach (Brunsdon, 2001) employs a very different technique to visualise changes in risk maps over time. The idea of the comap is an extension of Cleveland's (1993) coplot, or conditional plot. This is a plotting method that makes use of Tufte's idea of using 'small multiples' of diagrams to highlight differences in pattern. In particular, coplot are used to examine the relationship between a pair of variables ( $x$ and $y$, say) conditioned on the value of some third variable $(z)$. The question such plots are intended to investigate is 'How does the relationship between $x$ and $y$ vary given the value of $z$ ?'. The relationship between $x$ and $y$ is typically illustrated using a traditional technique such as a scatter plot (possibly with some kind of trend curve imposed on it). To investigate this phenomena, we select a number of subsets of the data, on the basis of queries on the range of the $z$ variable. That is, for a subset $k$ we select observations $\left(x_{i}, y_{i}\right)$ of the data set such that $z_{i} 2\left[a_{k}, b_{k}\right]-$ that is, $z$ is in the range between $a_{k}$ and $b_{k}$. Having selected a subset we then create a scatter plot of the $\left(x_{i}, y_{i}\right)$ 's selected on this basis. Selecting a number of such subsets, for say $k=1 \ldots L$, we have a sequence of plots. The plots are then arranged in a rectangular set of panels, in order of the values of the $a_{k}$ and $b_{k}$ pairs. Seeing the plots arranged in this way, changes in the relationship between $x$ and $y$ as $z$ increases are rela- 
tively easy to identify. A number of guidelines for the creation of these panels of plots are set down:

- The ranges $\left[a_{k}, b_{k}\right]$ should overlap to some extent.

- The subsets of $x$ and $y$ should each contain the same number of observations.

- The plots in the sequence should be identical in all aspects (i.e. scale, notation, etc.) except for the data being shown.

Reasons for these are discussed in the papers by Cleveland (1993) and Brunsdon (2001). For our crime data, the variables $x$ and $y$ correspond to geographical location, and the $z$ variable is time. A basic coplot of 200 points selected randomly from the data is shown in Fig. 4. The plot has seven panels - the six roughly square plots are the sequence of scatter plots as described above. The broader panel at the top is called the 'given' panel and shows the $a_{k}$ and $b_{k}$ values graphically. Numbering the ranges in the panel from 1 to 6 , with lower ranges first, the corresponding six scatter plots are ordered as below:
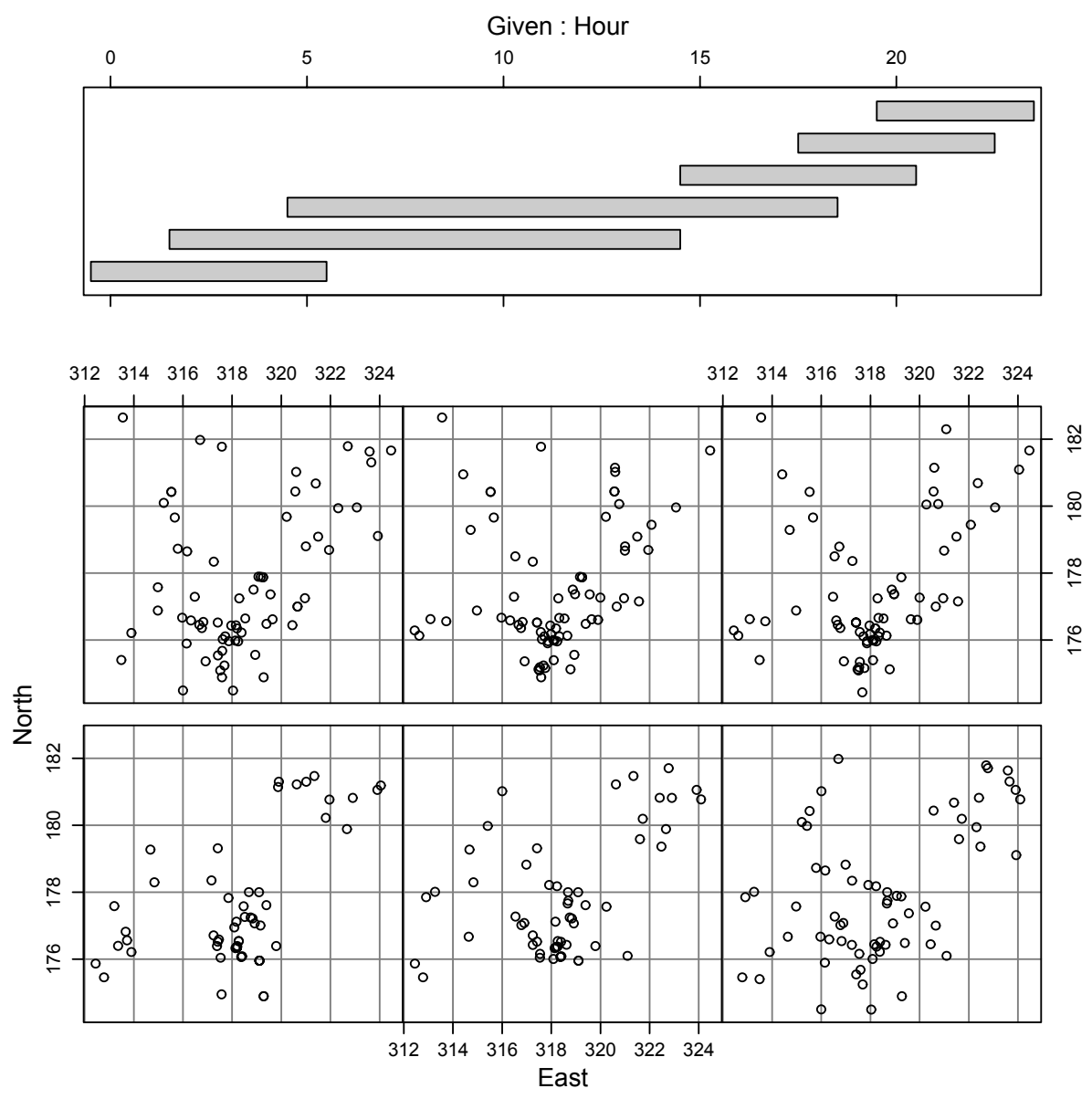

Fig. 4. A coplot applied to the disturbance data. 
$\begin{array}{lll}4 & 5 & 6\end{array}$

123

One effect that becomes apparent is a lower concentration of incidents in the central southern region in panels 1-3 compared to panels 4-6. Inspecting the 'given' panel suggests that these plots correspond to times in the early evening until around midnight.

However, the above example has a number of shortcomings. Firstly, it is based on a sample of 200 cases from a total of more than 13,000 - the subsampling is necessary since the scatter plots obtained with all cases are very difficult to read, with large areas effectively covered in ink. This makes it very difficult to assess relative densities of points (if it takes 200 points to cover a region with ink, then 2000 points in the same region would appear no different). For this size of data set, a kernel density plot (Silverman, 1986) - is more appropriate. Here an estimate of the probability density at the point $(x, y)$ is given by

$$
\text { fેx; yP } 1 / 4 \frac{1}{\mathrm{nh}_{1}^{2}}{ }^{\mathrm{X} 1 / 41} \mathrm{k}_{1} \frac{\mathrm{x} \quad \mathrm{x}_{\mathrm{i}}}{\mathrm{h}_{1}} ; \frac{\mathrm{y} \mathrm{y}_{\mathrm{i}}}{\mathrm{h}_{1}}
$$

ð1P

where $k_{1}\left(\mathbb{A}\right.$ ) is a probability density function defined over $2 \mathrm{~d}$ space, $h_{1}$ is the bandwidth of the estimate (a tuning parameter controlling the smoothness of the estimate), and $n$ is the number of observations of the form $\left(x_{i}, y_{i}\right)$ for $i=1 \ldots n$. In essence this is very similar to the 'hot-spot' maps discussed earlier. More details of kernel density estimation techniques, and in particular methods of choosing values for the bandwidth may be found, for example, in Silverman (1986).

Secondly, given that this is essentially geographical data, it may be more appropriate to use maps in the panels instead of scatterplot. The main distinction here is that a map may provide geographical context, such as an outline of the study area, or locations of major roads, boundaries to urban areas and so on. If the panels used are maps, then the diagram becomes a comap as coined by Brunsdon (2001). Comaps showing kernel density estimates of the full data set ${ }^{1}$ are given in Fig. 5 .

Here $k_{1}$ ( $\mathbb{E}$ - is a bisquare kernel, and the bandwidth was chosen according to the method set out in Brunsdon (2001). One clear effect is that although there appear to be two 'hot-spots' at some times of the day, a 'channel' appears between them at other times of day - namely during the daytime and the early evening. Also at certain times of day other smaller hotspots appear. As before, the guidelines for the maps are adhered to - the time intervals overlap, each kernel density estimate is based on the same sample size, and all characteristics of the maps not depending on the data are held fixed. In this case, the characteristics in question are scale, and the mapping between kernel estimate intensity and shading. In this case, the latter was implemented in a relative sense - the most intense shading contains $50 \%$ of all estimated incidents, and the next level contains $75 \%$ - this will be discussed further in Section 4.3. This suggests that the relative spread of incidents changes throughout the day, with a notable proportion of incidents occurring along a path connecting the two major hotspots at certain times. Finally, it is also possible to produce comaps conditioned on two variables. One such example is shown in Fig. 6.

Here the variables are time of day (as before) and day of week. Since day of week is a categorical variable it must be treated in a slightly different way. Here subsetting is

\footnotetext{
${ }^{1}$ Here, the maps have been distorted to maintain anonymity of the data
} 

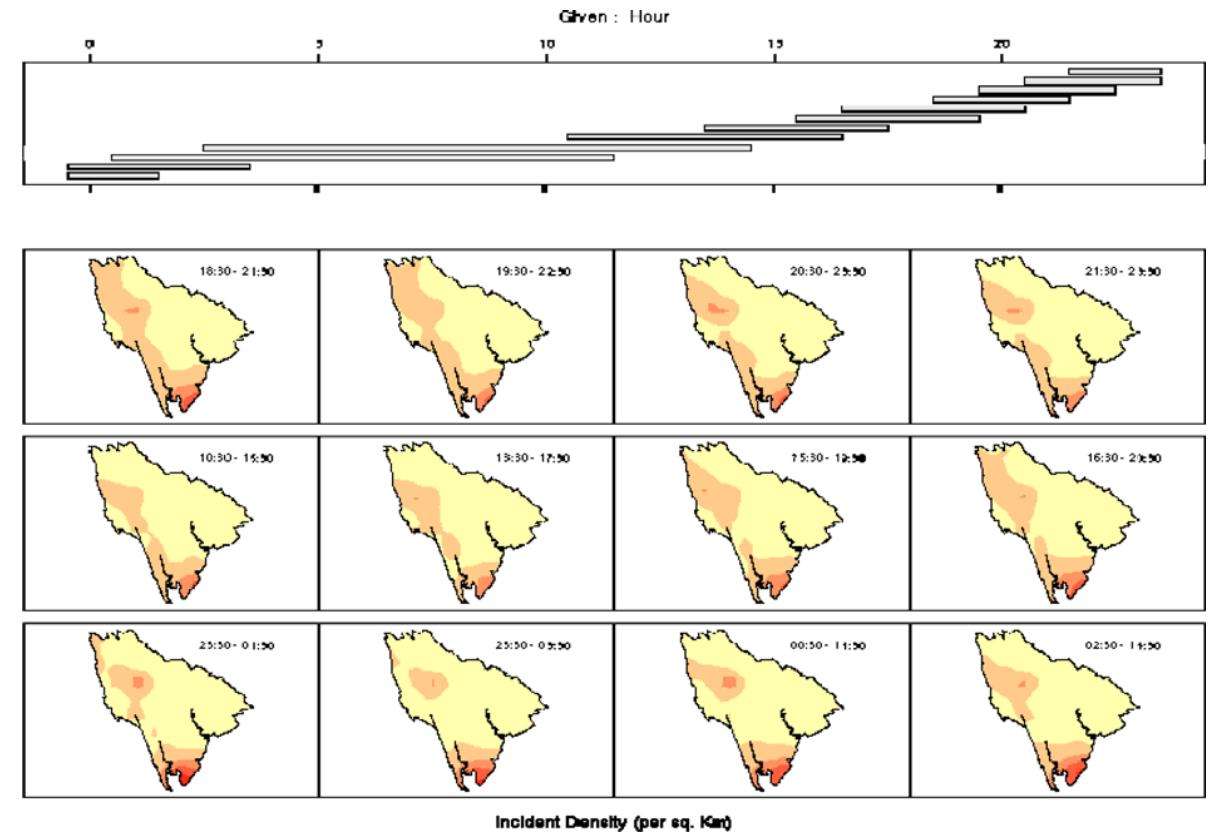

Fig. 5. Comap showing spatial distribution of disturbances conditioned on time of day.
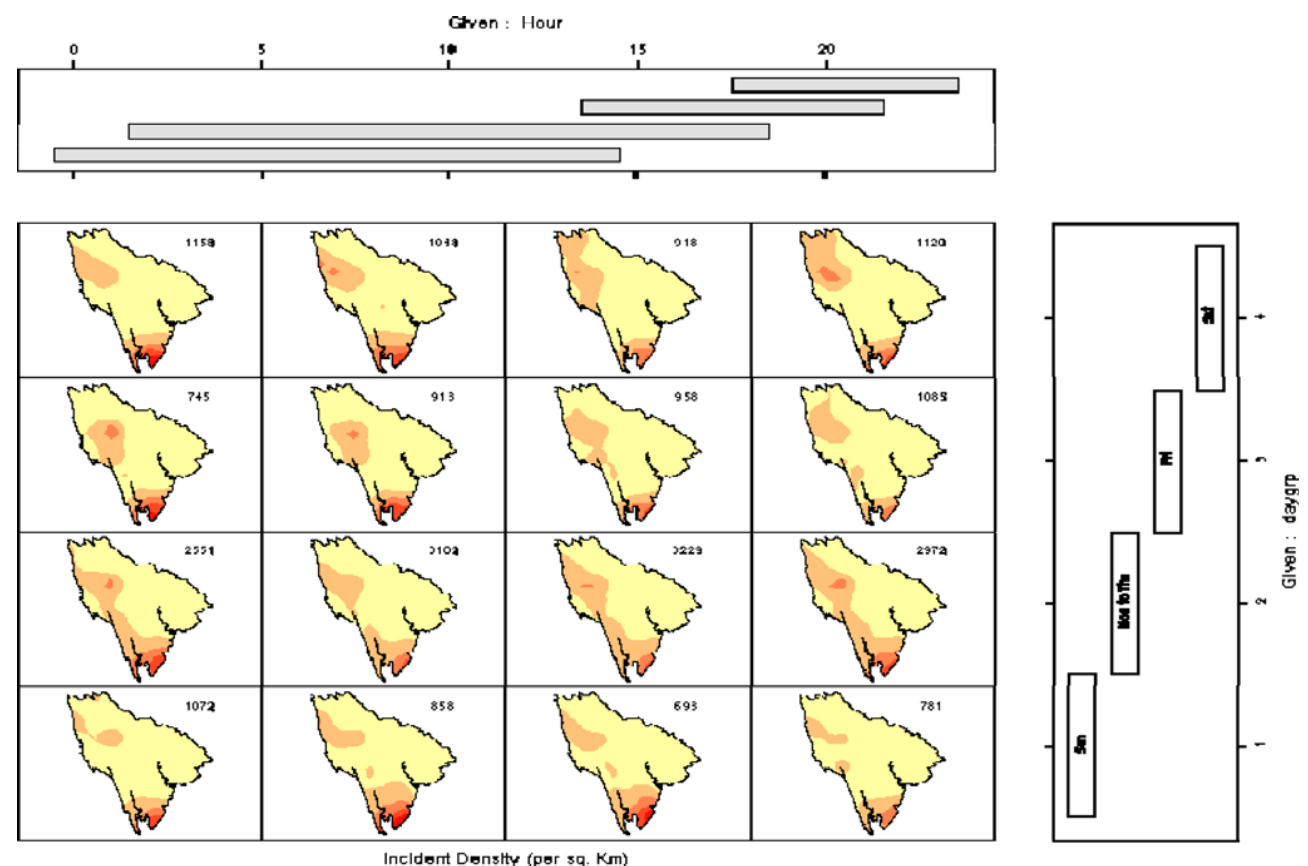

Fig. 6. Comap showing weekly and daily patterns. 
achieved by selecting subsets of the days, and it is no longer possible to select subsets with the same numbers of observations. However, despite these limitations some useful observations may still be made - notably that the 'path effect' discussed above seems more prominent on some days of the week than others - it is particularly notable on Mondays to Thursdays.

\subsection{The isosurface approach}

The isosurface provides yet another approach to investigating space-time phenomena. Like the comap, this approach allows the pattern of crime over an entire day (or possibly week) to be seen at once. The approach here is to consider each reported incidence as a point in space-time $(x, y, t)$ - usually the spatial part is regarded as two-dimensional. These triplets are then used as input to a three-dimensional kernel density estimation algorithm which attempts to estimate the probability density function $f(x, y, t)$. The value of this function reflects the likelihood of an incident occurring at location $(x, y)$ at time $t$. The formula for the kernel density estimation in space and time is an extension of that given in the previous section:

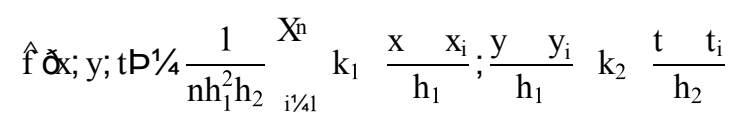

where the notation also seen in Eq. (1) is defined as there, $k_{2}($ f is a probability function defined over time with bandwidth $h_{2}$ and $n$ is the number of observations of the form $\left(x_{i}, y_{i}, t_{i}\right)$ for $i=1, \ldots, n$.

Unfortunately, to visualise such a kernel density estimate directly would require fourdimensional space - two dimensions for geographical space, one for time and one for the density estimation itself. However, the isosurface provides a way of visualising the density function (or at least some aspect of it) in three-dimensional space. For functions of three variables, an isosurface is the equivalent of the isoline or contour line for functions of two variables. That is, it is a two-dimensional surface embedded in three-dimensional space which joins together points having the same value (say $v$ ) of a function $f$ applied to the three arguments represented by the points. In this case, $f$ is the space-time kernel density. An example of an isosurface is shown in Fig. 7.

One important issue here is that of choosing the value $v$ for the isosurface. Typically, for functions of two variables contour line or isoline plots show several lines (for several values of $v$ ). However, for functions of three variables matters are more complex. Isolines are essentially one-dimensional objects (curves), but isosurfaces are two-dimensional. For this reason, difficulties arise when trying to show more than one value of $v$. In particular, in the same way that isolines of one value of $v$ often 'surround' isolines of another value in the $2 \mathrm{~d}$ space, isosurfaces of one value of $v$ 'surround' other isosurfaces in three-dimensional space - essentially enclosing them 'Russian doll'-style, and rendering them invisible. One possible approach to showing more than one isosurface in the same image is to draw an outer surface with a degree of translucence, so that a second surface enclosed in this is visible. Unfortunately we have found results to be disappointing - in many cases the isosurfaces are hard to identify, and the approach does not really work at all for more than 


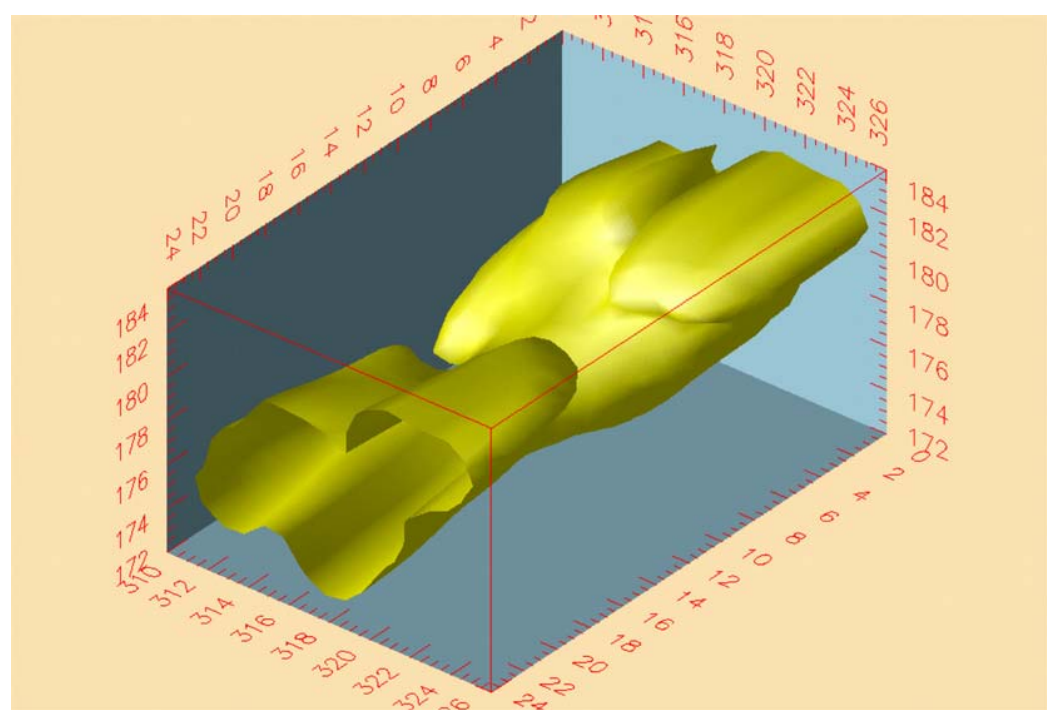

Fig. 7. Example of an isosurface.

two isosurfaces. We suggest an alternative approach, in which single isosurfaces are viewed interactively to obtain further insight into the 'shape' of $f$ in four-dimensional space.

The interactive approach is achieved using the OpenDX visualisation system. This is an open source interactive visualisation software package based on IBM's visualisation data explorer (see http://www.opendx.org). When inspecting an isosurface, the viewer may interact with it in the following ways:

- Varying the value of $v$.

- Varying the translucency of the isosurface.

- Rotation in three dimensions.

- Zooming-in and fly-through controls.

The choice of value of $v$ presents some interesting problems. Probability is a dimensionless quantity ${ }^{2}$, but probability density is not. In this case, the units of probability density are $\mathrm{m}^{2} \mathrm{~s}^{1}$ - and so the value of $v$ will be in these units. However, it is hard to interpret quantities in this dimension - so we consider $v$ as a function of $p$ : the relationship between $p$ and $v$ being that $p$ is the probability that a point occurs in a part of the $(x, y, t)$ space such that $f(x, y, t)>v$. The relationship may be written more formally as

$$
\begin{aligned}
& \text { Z Z Z } \\
& \mathrm{p}^{1 / 4} \quad \mathrm{f} \approx ; \mathrm{y} ; \mathrm{t}_{\mathrm{v}} \mathrm{f} \approx ; \mathrm{y} ; \mathrm{t} \not \mathrm{dxdydt}
\end{aligned}
$$

We can solve the above equation approximately by using a discrete sum to find $v$ for a given value of $p$. The utility of this can be seen, when for example $p=0.5$. In this case we find the isosurface containing exactly half of the expected incidents, according to the

\footnotetext{
${ }^{2}$ Being defined as a ratio between two integer counts
} 
kernel density model. This can be thought of as something similar to an interquartile range in the one-dimensional case. Other values of $p$ such as 0.25 and 0.75 also have reasonably easily understood interpretations. For this reason, the particular isosurface to be drawn is determined by a user control that specifies $p$ rather than $v$. This is essentially the same approach as used for contour shading in the comap example - although for comaps Eq. (3) would have only had the dimensions of space.

Finally, although visualisations of this kind can produce some striking and interesting patterns, it is relatively difficult to map interesting parts of the isosurface back into geographical space. For this reasons, we have also provided a facility where a two-dimensional 'slice' parallel to the $(x, y)$ plane may be moved up and down. This slice corresponds to a particular time of day. Linked to the motion of this sliding plane is a conventional two-dimensional hot-spot map. This map illustrates the geographical risk surface corresponding to the function $f(x, y, t)$ where $x$ and $y$ are treated as variable quantities and $t$ corresponds to the time indicated by the moving slice. A visualisation application having all of the above properties was created using OpenDX and is shown in Fig. 8.

Here, the time kernel $k_{2}($ f was a Von Mises distribution:

$$
\mathrm{k}_{2} \text { đP } 1 / 4 \text { wŏ } \operatorname{Pexp} \mathrm{j} \cos \frac{\mathrm{pt}}{12}
$$

ðా

where $\mathrm{j}$ is a constant related to the bandwidth $h_{2}$ and $\mathrm{w}(\mathrm{j})$ is a function chosen to normalise the distribution. This particular distribution was chosen because of its cyclic 'wrap-

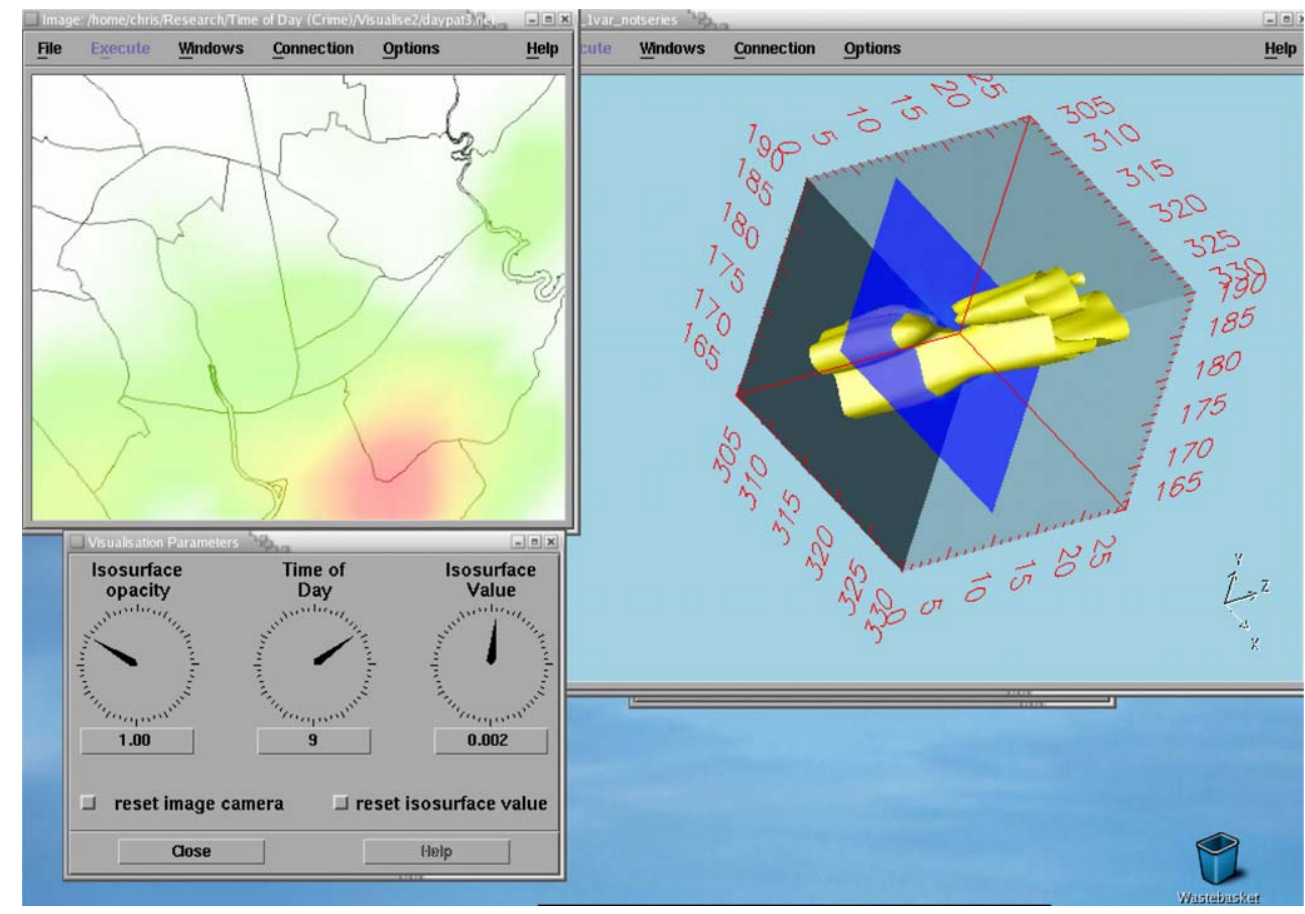

Fig. 8. OpenDX application to view a space-time crime isosurface. 
around' properties. In its given form, $k_{2}(t)=k_{2}(t+24)$ so that there is a seamless join in probability density between midnight on one day and the next. This representation differs from the comap in that densities are relative throughout the day, rather than throughout a given timeslice. In this format the 'path effect' is less marked suggesting that the increase of incidents along the path is relative to what else is happening at that time of day, rather than an absolute increase in crime numbers. However, the extra 'growths' appearing on the outside of the isosurface at certain times of day correspond to an increase of incidence in some areas (i.e. a set of 'satellite hotspots' as seen in the comaps). To identify these hotspots more readily, the map window in Fig. 8 could be inspected, having moved the blue slice to an appropriate location in the isosurface window. The map window shows the cross-section of the density estimate superimposed on an image of a map of the study area. In our example only a set of ward boundaries are shown to preserve anonymity, but in practice a fully featured raster map could be used.

\section{Linked plots}

One approach to assessing space-time interaction is to use linked plots. Common to the isosurface and comap, this approach also allows the pattern of crime over the entire time period under study to be seen at once. In this approach, a number of windows are drawn, each depicting one or two dimensional views of variables in the data, such as dot plots and scatter plots. In any window an object (usually a point, line or polygon) representing the variable value(s) for an individual observation may be selected, resulting in objects corresponding to the same observation in other windows being highlighted. For example, one could draw a point map (essentially a scatter plot) of geographical incident locations in one window, and a dot plot showing incident times in another. Selecting a set of points in the dot plot representing incidents occurring in a given time interval results in the geographical locations of the corresponding incidents being highlighted on the map. In this way it is possible to explore where incidents occurring at certain times of day are more likely to occur - and informally identify potential linkages between these variables (see Fig. 9).

There are a number of software packages for this kind of data exploration, such as Mondrian (Theus, 1998, 2005), cdv (Dykes, 1997b), lisp-stat (Tierney, 1990) and the iPlots library for the $R$ statistical software package (Urbanek \& Theus, 2003). One specific issue with time-of-day data is its cyclic nature - the variable (if represented as a decimal number) runs from 0 to 24 , but values just above 0 are close to values just below 24 , so that a simple linear scale does not represent this data adequately. This is particularly important when spotting trends - if activity peaks near to midnight, a linear dotplot 'breaks' the peak into two regions on the scale - one close to the left hand edge and the other close to the right hand edge. This could diminish the visual impact of the plot.

There are a number of methods for overcoming this problem - here we have used a circular dot plot (ref) to represent time of day. The software used to create the linked plots is Mondrian (Fig. 9). On the left is a scatterplot (essentially a point map) showing the locations of incidents, with axis labelling showing national grid coordinates obscured. On the right is a prototype circular dotplot showing time of day of reports of the incidents. Although Mondrian does not produce circular dotplots directly, they are achieved here by some pre-processing of the data. The price paid here is that the axes shown on the circular dot plot do not correspond to the values of the time-of-day variable. It is hoped that 


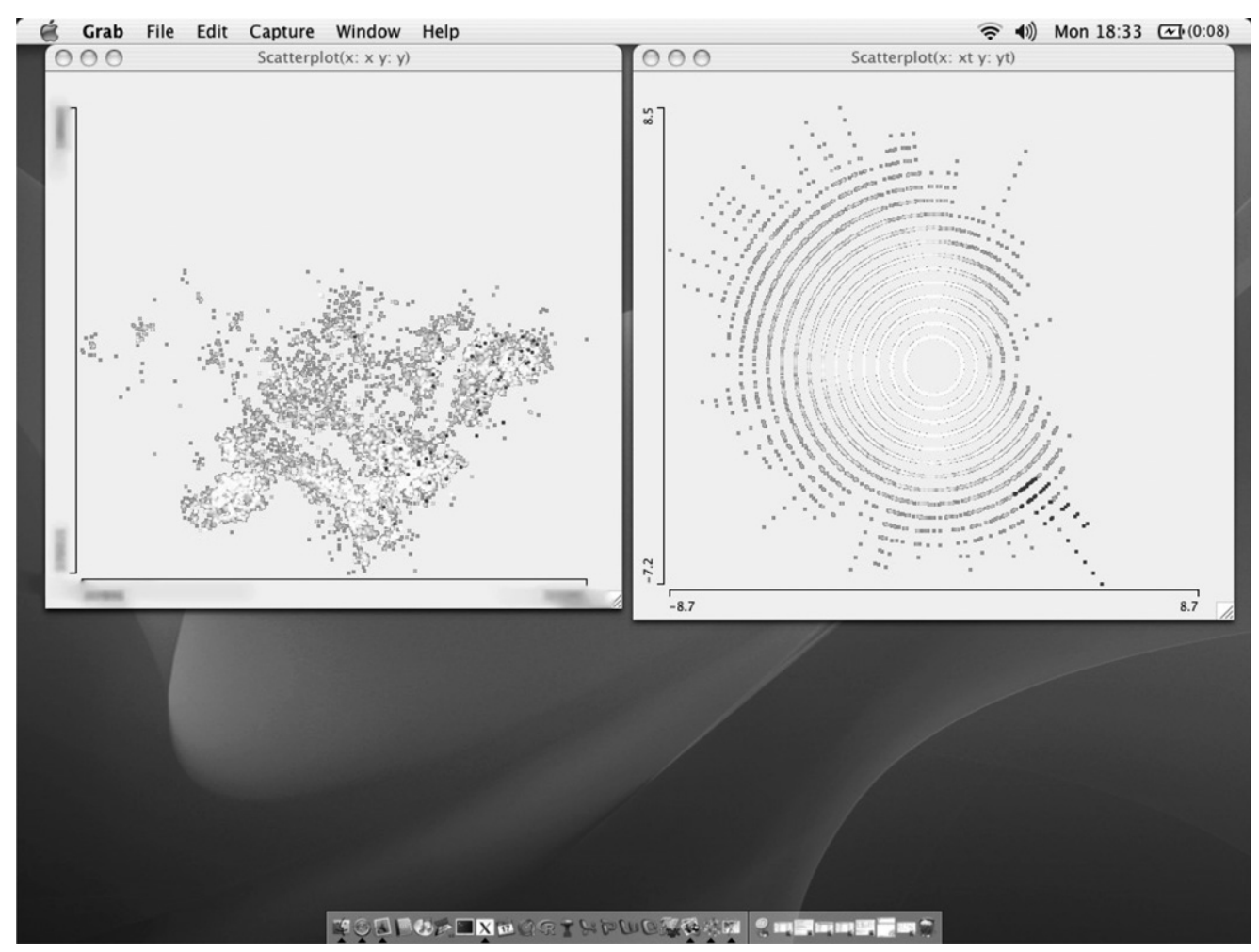

Fig. 9. Screenshot of Mondrian linked plots.

customised software will be produced in the future. In the figure, the number of events at around 10-11 am seems to peak compared to neighbouring times. These events are highlighted in the time-of-day plot, and on the map it can be seen that these all lie to the west of the study area - so that this sporadic peak of morning activity is geographically localized.

\section{Discussion}

Each of the techniques highlighted above have potential advantages (and limitations) for researchers interested in the exploratory visualisation of point level data; in this instance related to crime events (Table 2). Slocum et al. (2001) suggests more evidence is needed to show how users benefit from geovisualisation tools. Furthermore, as Fairbairn et al. (2001, p. 26) suggest, there is a clear need to "identify which representations are appropriate in which circumstances and match them to tasks (and users and data)." To date, whilst these techniques have been demonstrated to an audience of professionals charged with crime data analysis and mapping, we would suggest that a further avenue of research should involve demonstrating their relative effectiveness as an exploratory tool alongside the battery of other techniques available to such agencies. Following on from Hirschfields' (2001) findings that professionals in different agencies will have differing mapping and analytical requirements a potentially profitable angle of research could involve an evaluation of the effectiveness of such tools when applied to a variety of crime related 
Table 2

Respective advantages/disadvantages of techniques employed in this study

\begin{tabular}{|c|c|c|}
\hline Technique & Advantages & Disadvantages \\
\hline Comap & $\begin{array}{l}\text { - Able to show the patterns from the } \\
\text { whole time period under study } \\
\text { - Makes good use of Tufte's princi- } \\
\text { ple of 'small multiples' }\end{array}$ & $\begin{array}{l}\text { - Potentially complex to interpret } \\
\text { - Requires some familiarisation with the underlying } \\
\text { idea }\end{array}$ \\
\hline Isosurface & $\begin{array}{l}\text { - Able to show the patterns from the } \\
\text { whole time period under study } \\
\text { - Allows a large degree of interaction }\end{array}$ & $\begin{array}{l}\text { - Mathematically abstract } \\
\text { - Like comaps, require some familiarisation with the } \\
\text { underlying idea }\end{array}$ \\
\hline Animation & $\begin{array}{l}\text { - Intuitive } \\
\text { - Can link in with a lap-timer (or } \\
\text { snapshot) } \\
\text { - Simulation of movement provides } \\
\text { user with a }\end{array}$ & $\begin{array}{l}\text { - Associating a proper time with various points in the } \\
\text { animation } \\
\text { - Can be hard to understand - need to be interactively } \\
\text { controlled } \\
\text { - Can be difficult to interpret patterns when there are } \\
\text { large spatial variations been subsequent epochs }\end{array}$ \\
\hline $\begin{array}{r}\text { Linked } \\
\text { plots }\end{array}$ & $\begin{array}{l}\text { - Able to show the patterns from the } \\
\text { whole time period under study } \\
\text { - Allows a large degree of interaction }\end{array}$ & $\begin{array}{l}\text { - Potentially complex to interpret } \\
\text { - Can consume excessive computer resources and run } \\
\text { slowly if data set is fairly large }\end{array}$ \\
\hline
\end{tabular}

data sets. Williamson et al. (2001) have compared the use of spatial analysis tools (such as block aggregation, Voronoi diagrams, kernel smoothing and animation) in monitoring changes in crime patterns over time. In this paper, we have been concerned with applying innovative visualisation techniques in the exploratory analysis of crime data. There are important questions emanating from the research conducted here which that need to be addressed in future work. For example, there is a relative lack of research, certainly in the UK context, concerned with investigating the effectiveness of such techniques in the day-to-day work of crime analysts and intelligence officers. As Fairbairn et al. (2001, p. 16) suggest "study of the impact of new media displays, interaction of users with them and the reaction of users to them will be helpful in determining appropriate representations." More research is needed to gauge the usefulness of such representations in knowledge discovery and to gather feedback on the effectiveness of the techniques in an operational sense. Follow up research could involve questions that address the following:

- Are these tools capable of providing insights other tools are incapable of providing?

- How user-friendly and interpretative are the patterns provided by each of the techniques?

- What degree of computer proficiency is required to permit user-interaction with the visualisation techniques presented?

- How do the patterns of crime events revealed by such techniques compare to the perceptions of those charged with dealing with such offences "on the ground"?

A second potential strand of research, which we have not considered in the current paper, but that could be influential in the detection of patterns, relates to the inaccuracies in data sources. There is a clear need to consider the implications on resultant patterns of errors such as coding problems, inaccurate geo-coding of events and other sources of error. Further research is needed related to the incorporation of uncertainty error into visualisation techniques. Previous research has shown how variations in the reliability of geo-referenced 
data can be represented and communicated to potential users (see for example Ehlschlaeger, Shortridge, \& Goodchild, 1997; Evans, 1997; MacEachren et al., 1998). A potentially fruitful area of research could relate to the implications of such errors on resultant patterns of crime events. Again this should involve user testing - in particular interviews and trials involving crime pattern analysts and police officers who are potential end-users of this technology.

A number of other questions specifically related to the data sets and techniques employed in this study could also form the basis of further study. Clearly, there is the need to conduct similar analysis with other data sets (including those related to other types of crime) and to examine potential relationships between patterns of incidences. We are also in the process of incorporating other ancillary data sets such as opening and closing times of bars and other establishments and the dates and times of important sporting and entertainment events, which may have an impact on the patterns revealed in the study and which may help to explain trends. Other data sets related to socio-economic circumstances (e.g. deprivation profiles, geodemographic data) could also prove useful here. Once such data sets are in place, an extension of the isosurface to include metrics for comparing two or more isosurfaces and the introduction of event markers to indicate temporally significant localities for example large sporting events, pub/club opening time and taxi ranks could aid the interpretation of patterns and help in deployment of resources at specific time periods and locations.

Another avenue of research relates to the need to examine the potential of pre-processing techniques other than KDE: In this paper the visualisation methods are applied using some kind of smoothing algorithm - typically a kernel density estimate. The overall process could be regarded as pre-processing the data, and pipelining the result into some kind of visualisation tool. However, there is no reason why the pre-processing must always be a kernel-smoothing algorithm. One alternative possibility may be to use some space or space-time cluster detector (such as the Geographical Analysis Machine (GAM) - Turton $\&$ Openshaw, 2001) as a pre-processor in order to identify changes in likely cluster locations throughout the day.

Finally, in common with many researchers in this area, we have had to anonymise the area of study and distort the patterns in order not to reveal detailed specific patterns to audiences other than the providers of the data. Problems such as the stigmatisation of areas following the publications of such maps mean that in this paper we are not in a position to comment on detailed patterns of crime for the study area in question. A number of research groups are investigating the use of masking techniques in relation to crime (Leitner \& Curtis, 2004) and health (Armstrong, Rushton, \& Zimmerman, 1999) data respectively. Given the sensitive nature of these data sets, there is a clear need to incorporate ethical considerations into such analysis. However, whilst recognising that further research is needed to apply these techniques to other sources of crime data in order to permit a comprehensive evaluation of their respective strengths and limitations, we believe the research conducted to date has demonstrated that they have the potential to provide real insights into trends in both space and time.

\section{References}

Acevedo, W., \& Masuoka, P. (1997). Time-series animation techniques for visualising urban growth. Computers \& Geosciences, 23, 423-435. 
Armstrong, M. P., Rushton, G., \& Zimmerman, D. L. (1999). Geographically masking health data to preserve confidentiality. Statistics in Medicine, 18, 497-525.

Andrienko, G., \& Andrienko, N. (1999). Interactive maps for visual data exploration. International Journal of Geographical Information Science, 13, 355-374.

Andrienko, N., Andrienko, G., \& Gatalsky, P. (2003). Exploratory spatio-temporal visualisation: an analytical review. Journal of Visual Languages and Computing, 14, 503-541.

Batty, M. (1995). Animating urban dynamics: Using GIS to visualise space-time histories and predictions of cities from the industrial to post-industrial eras (pp. 44-55). RRLNET Lecture GISRUK, Newcastle, UK.

Bowers, K. J., \& Johnson, S. D. (2003). Measuring the geographical displacement and diffusion of benefit effects of crime prevention activity. Journal of Quantitative Criminology, 19, 275-301.

Brimicombe, A. J., Ralphs, M. P., Sampson, A., \& Tsui, H. Y. (2001). An analysis of the role of neighbourhood ethnic composition in the geographical distribution of racially motivated incidents. British Journal of Criminology, 41, 293-308.

Brunsdon, C. (2001). The comap: Exploring spatial pattern via conditional distributions. Computers, Environment and Urban Systems, 25, 53-68.

Cleveland, W. S. (1993). Visualizing data. USA: Hobart Press.

Corcoran, J., \& Ware, J. A. (2002). Helping with enquiries. Geo:Connexion, 1, 36-40.

Curtis, A., Leitner, M., \& Hanlon, C. (2002). Using hierarchical nearest neighbor analysis and animation to investigate the spatial and temporal patterns of raccoon rabies in west Virgina. In O. A. Khan \& R. Skinner (Eds.), Geographic information systems \& health applications (pp. 155-171). PA, USA: Idea Group Publishing.

DiBiase, D., MacEachren, A., Krygier, J., \& Reeves, C. (1992). Animation and the role of map design in scientific visualisation. Cartography and Geographical Information Systems, 19, 201-214.

Dorling, D. (1992). Stretching space and splicing time: From cartographic animation to interactive visualisation. Cartography and Geographic Information Systems, 19, 215-227.

Dorling, D., \& Openshaw, S. (1991). Experiments using computer animation to visualise space-time patterns. In Proceedings of second international conference on computers in urban planning and management (pp. 391-406). Oxford

Dykes, J. A. (1996). Dynamic maps for spatial science: a unified approach to cartographic visualisation. In D. Parker (Ed.), Innovation sin GIS 3 (pp. 177-187). Taylor and Francis.

Dykes, J. A. (1997a). Exploring spatial data representation with dynamic graphics. Computers \& GeoSciences, 23, $345-370$.

Dykes, J. A. (1997b). cdv: A flexible approach to ESDA with free demonstration software. In Proceedings, British Cartographic Society, 34th Annual Symposium (pp. 100-107). Leicester.

Ehlschlaeger, C. R., Shortridge, A. M., \& Goodchild, M. F. (1997). Visualising spatial data uncertainty using animation. Computers and GeoSciences, 23, 387-395.

Evans, B. (1997). Cartographic representation of reliability, does it benefit the user? Computers \& GeoSciences, 23, $409-422$.

Fairbairn, D., Andrienko, G., Andrienko, N., Buziek, G., \& Dykes, J. (2001). Representation and its relationship with cartographic visualisation. Cartography and Geographic Information Science, 28, 13-28.

Gimenez, R. A. (2001). Image viewer with thumbnail capabilities. <http://www.freevbcode.com/ShowCode Asp?ID=3451>. Accessed 04.05.2004.

Goldsmith, V., McGuire, P. G., Mollenkopf, J. H., \& Ross, T. A. (Eds.) (2000). Analysing crime patterns. Frontiers of practice. Washington, DC: National Institute of Justice.

Gould, P. (1989). Geographic dimensions of the AIDS epidemic. The Professional Geographer, 41(1), 71-78.

Guerry, A. M. (1833). Essai sur la statistique morale de la France. Westminster Review, 18, 357.

Haining, R. P., Wise, S. M., \& Ma, J. (1996). The design of a software system for the interactive spatial statistical analysis linked to a GIS. Computational Statistics, 11, 449-466.

Haslett, J., Wills, G., \& Unwin, A. (1990). SPIDER - an interactive statistical tool for the analysis of spatially distributed data. International Journal of GIS, 4(3), 285-296.

Hirschfield, A. (2001). Decision support in crime prevention; data analysis, policy evaluation and GIS. In A. Hirschfield \& K. Bowers (Eds.), Mapping and analysis of crime data (pp. 237-268). London: Taylor and Francis.

Hirschfield, A., \& Bowers, K. (Eds.) (2002). Mapping and analysis of crime data. London: Taylor and Francis.

Hooge, P. N., \& Eichenlaub, B. (2000). Animal movement extension to ArcView. Anchorage, AK, USA, Alaska Science Center - Biological Science Office, US Geological Survey. 
Johnson, I. (1997). Mapping the fourth dimension: The TimeMap Project. In Proceedings of the 1997 computer applications in archaeology. Oxford, UK: Archeopress.

Koussoulakou, A., \& Kraak, M.-J. (1992). Spatio-temporal maps and cartographic communication. Cartographic Journal, 29, 101-108.

Langworthy, R. H., \& Jefferis, E. S. (2000). The utility of standard deviation ellipses for evaluating hotspots. In V. Goldsmith et al. (Eds.), Analyzing crime patterns (pp. 87-104). Thousand Oaks, CA: Sage.

Leipnik, M. R., \& Albert, D. P. (2003). GIS in law enforcement: Implementation issues and case studies. London: Taylor and Francis.

Leitner, M., \& Curtis, A. (2004). Visualising the location of confidential crime data, Paper presented at the 7 th Annual International Crime Mapping Conference, Boston, March 2004.

Levine, N. (1999). Development of a spatial analysis toolkit for use in a metropolitan crime incident geographic information system. Washington DC: National Institute of Justice.

MacDougall, E. B. (1992). Exploratory analysis, dynamic statistical visualisation and geographic information systems. Cartography and Geographic Information Systems, 19, 237-246.

MacEachren, A. M. (1994). Visualisation in cartography: setting the agenda. In A. M. MacEachren \& D. R. F. Taylor (Eds.), Visualisation in modern cartography (pp. 1-12). Oxford: Permagon.

MacEachren, A. M., Boscoe, F. P., Haug, D., \& Pickle, L. W. (1998). Geographic visualisation: designing manipulable maps for exploring temporally varying georeferenced statistics. In Proceedings information visualisation '98 (pp. 87-94). IEEE Computer Society Press.

MacEachren, A. M., \& Kraak, M.-J. (2001). Research challenges in Geovisualisation. Cartography and Geographic Information Science, 28, 3-12.

Mamalian, C. A., \& LaVigne, N. G. (1999). The use of computerised crime mapping by law enforcement: Survey results. National Institute of Justice Research Preview. <http://www.ncjrs.org/pdffiles1/fs000237.pdf>. Accessed 27.04.2004.

McEwen, J. T., \& Taxman, F. S. (1995). Applications of computer mapping to police operations. In J. E. Eck \& D. Weisburd (Eds.), Crime and llace (pp. 259-284). Monsey, NY, Washington, DC: Criminal Justice Press, Police Executive Research Forum.

McLafferty, S., Williamson, D., \& McGuire, P. G. (2000). Identifying crime hotspots using kernel smoothing. In V. Goldsmith et al. (Eds.), Analyzing crime patterns (pp. 77-85). Thousand Oaks, CA: Sage.

Moellering, H. (1976). The potential uses of computer animated film in the analysis of geographical patterns of traffic crashes. Accident Analysis \& Prevention, 8, 215-227.

Morrison, J. B., Tversky, B., \& Betrancourt, M. (2000). Animation; Does it facilitate learning? In: Proceedings Smart Graphics 2000: AAAI Spring symposium, Stanford, California.

Openshaw, S., Charlton, M., Craft, A. W., \& Birch, J. M. (1988). Investigation of leukaemia clusters by the use of a geographical information system. The Lancet, 1, 272-273.

Openshaw, S., \& Dorling, D. (1992). Using computer animation to visualise space-time patterns. Environment and Planning B: Planning and Design, 19, 639-650.

Openshaw, S., Waugh, D., \& Cross, A. (1994). Some ideas about the use of animation as a spatial analysis tool. In H. W. Hearnshaw \& D. J. Unwin (Eds.), Visualisation in GIS. John Wiley \& Sons Ltd.

Pellenbarg, P. H., \& Van Steen, P. J. M. (2000). Crime in the Netherlands. Introduction to the 2000 Maps. Journal of Economic and Social Geography, 91, 106-107.

Quètelet, A. (1842). A treatise on man. Edinburgh, Chambers.

Shepherd, I. D. H. (1995). Putting time on the map: dynamic displays in data visualisation and GIS. In P. F. Fisher (Ed.), Innovations in GIS 2 (pp. 169-187). London: Taylor and Francis.

Sherman, L. W., Gartin, P. R., \& Buerger, M. E. (1989). Hot spots of predatory crime: Routine activities and the criminology of place. Criminology, 27, 27-55.

Silverman, B. W. (1986). Probability density estimation for statistics and data analysis. New York: Chapman and Hall.

Slocum, T. A., Blok, C., Jiang, B., Koussoulakou, A., Montello, D. R., Fuhrmann, S., et al. (2001). Cognitive and usability issues in geovisualisation. Cartography and Geographic Information Science, 28, 61-75.

Slocum, T. A., \& Egbert, S. L. (1993). Knowledge acquisition from choropleth maps. Cartography and Geographic Information Systems, 20, 83-95.

Theus, M. (2005). MONDRIAN - Interactive Statistical Visualisation in JAVA $<$ http://rosuda.org/Mondrian/ $>$. Accessed 24.05.2005.

Theus, M. (1998). MONDRIAN - Interactive graphical data analysis graphics workshop. Madison, NJ: Drew University. 
Thomas, C. J., Nelson, A. L., \& Bromley, R. D. F. (1996). The geography of shoplifting in a British city: Evidence from Cardiff. Geoforum, 27, 409-423.

Tierney, L. (1990). LISP-STAT: An object-oriented environment for statistical computing and dynamic graphics. Wiley.

Tobler, W. R. (1970). A computer movie simulating urban growth in the Detroit region. Economic Geography, 46, 234-240.

Turton, I., \& Openshaw, S. (2001). Methods for automating the geographical analysis of crime incident data. In A. Hirschfield \& K. Bowers (Eds.), Mapping and analysis of crime data (pp. 11-26). London: Taylor and Francis.

Urbanek, S., \& Theus, M. (2003). iPlots: High interaction graphics for R, <http://www.ci.tuwien.ac.at/ Conferences/DSC-2003/Proceedings/UrbanekTheus.pdf $>$. Accessed 24.05.2005.

Venezia, J., \& Kane, K. (2002). Using 3D urban models and tools to assist in public safety and provide law enforcement solutions. Crime Mapping News, 4, 1-4.

Weisburd, D., \& McEwen, T. (Eds.) (1998). Crime mapping-crime prevention. Crime prevention studies (vol. 8). New York: Criminal Justice Press.

Williamson, D., McLafferty, S., McGuire, P., Ross, T., Mollenkopf, J., Goldsmith, V., \& Quinn, S. (2001). Tools in the spatial analysis of crime. In A. Hirschfield \& K. Bowers (Eds.), Mapping and analysis of crime data (pp. 187-202). London: Taylor and Francis. 